other animals were inseminated after return to heat 20 days post treatment (control group). Parallel to that, the effect of the number of spermatozoa per insemination was studied.

Three gilts out of four systematically inseminated on days 6 and 7 after the treatment were in oestrus according to the observations of the farmer. In the control group $6 \mathrm{p}$. I oo of the animals were not inseminated because they did not return to heat. The variability of the results was essentially due to differences between herds in the number of animals with delayed puberty. Like all progestagens, " RU 2267 " had only an effect on puberal gilts. On the other hand, grouping of oestruses was better when the gilts were fed individually.

This technique allows to control the cycles without detection of ostrus and to use A.I. on days fixed in advance. As a matter of fact, when the progestagen was distributed individually, the farrowing rate after systematic insemination with $12.0^{9}$ spermatozoa was 68.5 p. I 100 (9.8 piglets born alive on an average), a result similar to that of the controls $(58 \mathrm{p}$. I00; I0.3 piglets born alive). The fertility after induction of ostrus (percentages calculated from animals in heat at the moment of irisemination) was nearly $7^{\circ} \mathrm{p}$. I oo. However, better results were obtained after use of $12.10^{9}$ spermatozoa when the progestagen was given individually (farrowing rate: 87.2 p. Ioo; 9.8 piglets born alive on an average). A similar effect was not observed int the corresponding control group (farrowing rate: $67.5 \mathrm{p}$. I00; 10.3 piglets born alive on an average). The progestagens seem to have a depressive effect on survival and migration of spermatozoa in the female genital tract, as often observed in the other species.

\title{
Better control of post lactation oestrus by means of a progestagen (RU 2267)
}

\author{
Françoise MARTINAT-BOTTE $\left({ }^{1}\right)$, F. BARITEAU $\left({ }^{2}\right)$, J. GAUTIER $\left({ }^{2}\right)$, P. MAULÉON ( \\ (1) I.T.P., I49, rue de Bercy, 75595 Pavis Cedex I2 \\ (2) Station de physiologie de la Reproduction, \\ Centre de Recherches de Tours, I.N.R.A., \\ Nouzilly, 37380 Monnaie (France)
}

Suckling sows were given a component possessing a progestative activity RU 2267 for 7 days ( 3 days before drying off, the very same day, three days after). At the end of the treatment, sows were systematically inseminated on days 6 or 7 (in cestrus or not). The control females of the same age as the former ones were inseminated after the onset of cestrus (double artificial insemination at 24 hours interval). The effect of the number of spermatozoa per insemination was studied.

In the suckling sow, the progestagen RU 2267 at the dose of $30 \mathrm{mg} / \mathrm{sow} / \mathrm{day}$ had a depressive effect on the return to cestrus: II.5 p. I oo females were not in heat at the moment of systematic inseminations, versus I p. Ioo in the controls. This might be due to the progestagen concentration. Moreover, the fertility was very low: $53 \mathrm{p}$. I 100 farrowed 9.2 piglets on an average (a total of $\mathrm{I}+3$ sows). Higher fertility and prolificacy were noticed in the controls: $70.6 \mathrm{p}$. Ioo and ro.6 piglets (a difference of r.5 pigiets was observed between control and treated sows). On the contrary, when analysing these results relative to the number of spermatozoa employed for AI, a substantial improvement of the farrowing rate was noticed with $6.10^{9}$ spermatozoa/AI instead of $3.10^{9}$ and without any overfeeding after the end of the progestative treatment (76.2 versus 48.8 p. Ioo). Prolificacy remained always lower than that of the controls. 